\title{
The applications of augmented reality for universal access in online education
}

\author{
Chia-Wen Tsai ${ }^{1}$
}

Published online: 2 November 2017

(c) Springer-Verlag GmbH Germany 2017

Augmented reality (AR) refers to a technology that overlays virtual objects into the real world [1], and can be created by applying and connecting various technologies, such as wearable computers, mobile devices, and immersion technologies [9]. AR is applied in different fields, including (a) industry and military, (b) training and education, (c) travel and tourism, (d) medicine and health care, and (e) retail and marketing [6]. It has gained much research attention in recent years as new possibilities and innovative applications for teaching and learning provided by AR have been recognized by educational researchers [10]. AR brings new opportunities and channels for teaching and education, and can be helpful in addressing various students' difficulties with learning and understanding subjects such as chemistry [4]. In addition, AR also provides huge opportunities for online education, especially in disciplines that place emphasis on practical training and are unsuited for non-classroom training [2]. Moreover, AR-based mobile learning material can help learners engage in numerous learning activities [5]. It is also reported that the number of AR and online education studies has significantly increased since 2009 [8]. Thus, it is believed that AR is an important topic in the fields of information technology, education, and the information society.

Due to the increasing popularity of AR in the educational and training fields [1], the guest editor facilitated this special issue to collect research studies that investigate various design and applications of AR to help support better learning achievements. The authors of the nine papers in this special

Chia-Wen Tsai

jawen12b@gmail.com

1 Department of Information Management, Ming Chuan University, 250 Zhong-Shan N. Road Sec. 5, Taipei,

Taiwan, ROC issue present different approaches and several applications of AR in learning and training. Each of these nine papers went through two rounds of review by peer reviewers and the guest editor's final review.

In the first paper "Effects of formative assessment in an augmented reality approach to conducting ubiquitous learning activities for architecture courses," by Hui-Chun Chu, Jun-Ming Chen, Gwo-Jen Hwang, and Tsung-Wen Chen, the authors present an AR-based learning system for an architecture course according to a formative assessment mechanism that helps learners to find answers by providing hints as they fail to answer questions correctly. The authors conducted an experiment with 39 students in the Museum of World Religions for an architecture course and found that AR-based learning with the formative assessment mechanism significantly enhances the learners' learning achievements and motivation, and also reduces their cognitive load.

The second paper "Enhancing students' botanical learning by using augmented reality," by Yu-Cheng Chien, YenNing Su, Ting-Ting Wu, Yueh-Min Huang, explores the effects on students' learning outcomes of AR-based learning materials adopted in this study to provide multifaceted views of plants. The authors designed realistic AR-based learning material for learning botany and integrated the material into a natural science course for third grade students. In this research, it is found that learners in the experimental group learning about plants through AR had significantly greater comprehension in conceptual analysis and identification of leaf arrangement than those in the control group. However, it is also reported that no significant statistical differences exist between the experimental and control groups with respect to levels of remembering and understanding.

Tzong-Hann Wu, Feng Wu, Ci-Jyun Liang, Yi-Fen Li, Ching-Mei Tseng, and Shih-Chung Kang, in their paper "A virtual reality tool for training in global engineering 
collaboration," introduce a global project-based course titled "Sky Classroom" that aimed to deliver global engineering collaboration skills, and facilitated students' collaboration in the design of buildings. The authors further designed a platform, the virtual building information modeling (BIM) reviewer (VBR), for solving students' problems in learning. It is reported that VBR could resolve the common issues in screen-sharing platforms, such as low communicability, passive problem finding, and poor spatial cognition. The authors in this research indicate that the adoption of the VBR in Sky Classroom not only solves the problems in the existing communication platform, but also helps students in collaboration.

In the paper "Effects of augmented reality-based multidimensional concept maps on students' learning achievement, motivation and acceptance," Chien-Hsu Chen, Chun-Yen Huang, and Yin-Yu Chou present an AR-based multidimensional concept map (ARMCM) learning system for elementary school students' mobile learning activities. The authors conducted an experiment, with an ARMCM group and a multidimensional concept map (MCM) group, to evaluate the effectiveness of their proposed approach. It is reported by the authors that students in the ARMCM group have significantly better performance, higher motivation, and higher acceptance of multidimensional concept maps than those in the MCM group. In addition, the authors also indicate that the students in the ARMCM group report higher perceived usefulness and perceived ease of use of learning approaches than those in the MCM group.

The fifth paper "Interactive safety education using Building Anatomy Modeling," presented by Hai Chien Pham, Akeem Pedro, Quang Tuan Le, Do-Yeop Lee, and Chan Sik Park, mentions that safety is usually regarded as a low priority, and safety education is delivered in isolation, without practical experience and sufficient interaction in many construction curricula. The authors thus present a Building Anatomy Concept (BAC) that integrates anatomical theory with advanced visualization technologies to improve tertiary construction safety education. From the perspective of this BAC, the authors designed an interactive construction safety education system integrating Building Anatomy Modeling (BAM), which comprises a Knowledge Acquisition Module (KAM) and a Practical Experience Module (PEM), to develop students' safety knowledge and skills. In this study, it is reported that students studying in the class using BAM have better learning performance than those in the traditional class with whiteboard lectures.

Shih-Jou Yu, Jerry Chih-Yuan Sun, and Oscal TzyhChiang Chen, in the paper entitled "Effect of AR-based online wearable guides on university students' situational interest and learning performance," explored whether ARbased online wearable guides result in better development of students' situational interest and learning achievement when compared with audio guides. The authors employed a museum as their research site and conducted an experiment with two groups (one group applying AR-based online wearable guides and the other applying audio guides). When compared with learners in the audio guide group, the AR-based online wearable guide increased their situational interest and this is helpful in developing learners' long-term interest in museum content. In addition, it is also reported that situational interest has a significantly positive correlation with the memory dimension of learning achievement in this study.

In the seventh article "Seeing creativity in an augmented experiential learning environment," by Tien-Chi Huang, the author introduces an innovative learning paradigm in outdoor co-space and a mobile AR-based system in the creative thinking unit of "e-Learning" course. This system consisted of a mobile application integrated with Google Glass, Android-based smartphone, and online platform and conducted a remote associates test (RAT). The AR-based system uses RAT to carry out question-generating and question-solving tasks in small groups, thus creating a social construction learning activity conducted in authentic environments. In this research, learners indicate that the authentic environment provides real stimuli to enhance the learning effectiveness of associations. In addition, it is also mentioned that the stimulation of question generation may be a more critical factor than that of question answering on remote associates in this study.

The eighth paper "Effects of gender and different augmented reality learning systems on the English vocabulary learning of elementary school students," by TingChia Hsu, presents the design and comparison of two AR learning systems for third grade students learning English vocabulary. The first AR learning system is developed according to Collective Game-Based (CGB) design, while the other is developed based on Sequential-Mission Gaming (SMG) design. The author reports that students who use the CGB system have higher flow experience and lower intrinsic cognitive loads than those who use the SMG system. In addition, it is also revealed that the females' flow experience in the CGB system outperforms those in the SMG system.

In the last paper of this special issue, entitled "Using augmented-reality-based training system to promote spatial visualization ability for elderly," Zheng-Yu Hoe, I-Jui Lee, Chien-Hsu Chen (also one of the authors of the fourth paper), and Kuo-Ping Chang present an AR-based system to train elderly people for their rehabilitation of spatial visualization ability. The authors applied AR technology integrated with a tangible user interface for elderly directly manipulating a virtual 3D model using a cube to conduct mental rotation tasks (MRTs) to improve their mental rotation ability. In this research, it is revealed that the AR-based spatial 
visualization training system decreases the elderly's error rate and reduces the reaction times during the MRT test.

It is suggested that system providers of online education should adapt their offerings to innovative developments and new learner needs [3]. Many educators have proposed that educational technologies are effective tools for students' learning [7]. The guest editor and the authors of the nine papers of this special issue hope that the applications of educational technologies, such as AR, for universal access in online education can provide useful reference and highlight implications for designers, teachers, and educators who plan to develop or design online courses with innovative applications of AR. Finally, the guest editor appreciates all the authors' contributions and the reviewers' careful review and valuable suggestions that led to the completion and success of this special issue.

\section{References}

1. Akçayır, M., Akçayır, G.: Advantages and challenges associated with augmented reality for education: a systematic review of the literature. Educ. Res. Rev. 20, 1-11 (2017)

2. Andújar, J.M., Mejías, A., Márquez, M.A.: Augmented reality for the improvement of remote laboratories: an augmented remote laboratory. IEEE Trans. Educ. 54(3), 492-500 (2011)
3. Dehbi, R.: Model driven engineering applied in e-learning development process: advanced comparative study with ROC multicriteria analysis. Int. J. Online Pedagogy Course Des. 7(1), 15-32 (2017)

4. Iordache, D.D., Pribeanu, C., Balog, A.: Influence of specific AR capabilities on the learning effectiveness and efficiency. Stud. Inform. Control 21(3), 233-240 (2012)

5. Liu, P.H.E., Tsai, M.K.: Using augmented-reality-based mobile learning material in EFL English composition: an exploratory case study. Br. J. Educ. Technol. 44(1), E1-E4 (2013). https:// doi.org/10.1111/j.1467-8535.2012.01302.x

6. Martínez, H., Skournetou, D., Hyppölä, J., Laukkanen, S., Heikkilä, A. (2014) Drivers and bottlenecks in the adoption of augmented reality applications. J. Multimed. Theory Appl. 1. http:// jmta.avestia.com/2014/PDF/004.pdf

7. Ojeda-Castro, A.M., Murray-Finley, P., Sánchez-Villafañe, J.: Learning management system use to increase mathematics knowledge and skills in Puerto Rico. Int. J. Technol. Human Interact. 13(2), 89-100 (2017)

8. Tsai, C.W., Shen, P.D., Fan, Y.T.: The application of augmented reality in online education: a review of studies published in selected journals from 2003 to 2012. Int. J. Inf. Commun. Technol. Educ. 10(2), 75-80 (2014)

9. Wei, X., Weng, D., Liu, Y., Wang, Y.: Teaching based on augmented reality for a technical creative design course. Comput. Educ. 81, 221-234 (2015)

10. Wu, H.K., Lee, S.W.Y., Chang, H.Y., Liang, J.C.: Current status, opportunities and challenges of augmented reality in education. Comput. Educ. 62, 41-49 (2013) 